\title{
Verwantschap weven : vertelpraktijken en culturele herinnering in transnationale adoptie
}

Citation for published version (APA):

Wesseling, E. (2014). Verwantschap weven : vertelpraktijken en culturele herinnering in transnationale adoptie. Maastricht University. https://doi.org/10.26481/spe.20140912ew

Document status and date:

Published: 12/09/2014

DOI:

$10.26481 /$ spe.20140912ew

Document Version:

Publisher's PDF, also known as Version of record

\section{Please check the document version of this publication:}

- A submitted manuscript is the version of the article upon submission and before peer-review. There can be important differences between the submitted version and the official published version of record.

People interested in the research are advised to contact the author for the final version of the publication, or visit the DOI to the publisher's website.

- The final author version and the galley proof are versions of the publication after peer review.

- The final published version features the final layout of the paper including the volume, issue and page numbers.

Link to publication

\footnotetext{
General rights rights.

- You may freely distribute the URL identifying the publication in the public portal. please follow below link for the End User Agreement:

www.umlib.nl/taverne-license

Take down policy

If you believe that this document breaches copyright please contact us at:

repository@maastrichtuniversity.nl

providing details and we will investigate your claim.
}

Copyright and moral rights for the publications made accessible in the public portal are retained by the authors and/or other copyright owners and it is a condition of accessing publications that users recognise and abide by the legal requirements associated with these

- Users may download and print one copy of any publication from the public portal for the purpose of private study or research.

- You may not further distribute the material or use it for any profit-making activity or commercial gain

If the publication is distributed under the terms of Article $25 \mathrm{fa}$ of the Dutch Copyright Act, indicated by the "Taverne" license above, 


\section{Maastricht University}

prof.dr. Lies Wesseling

Faculteit der Cultuur- en

Maatschappij-

wetenschappen

Verwantschap weven :

vertelpraktijken en

culturele herinnering in

transnationale adoptie 
Dames en heren,

Op welke gronden kunnen we verwantschap claimen? Zijn genen van doorslaggevend belang hier, of de dagelijkse verwantschapspraktijk? Is verwantschap gegeven, of wordt ze geweven? Deze eeuwenoude vragen worden onder druk van veranderende maatschappelijke omstandigheden telkens weer opnieuw actueel. De emancipatie van homoseksuelen leidde er bij voorbeeld toe dat we tegenwoordig gezinnen met twee vaders of twee moeders erkennen, waarvan hooguit één van de twee ouders een genetische band met de kinderen heeft. Daarnaast is transnationale en transraciale adoptie een gangbaar verschijnsel geworden in onze globaliserende wereld. In dit geval is genetische verwantschap zelfs categoriaal afwezig.

Gezinsvorming door middel van transnationale adoptie is een uitnodigend onderzoeksobject voor genderstudies, omdat het adoptiegezin de vraag naar het cultuurlijke dan wel natuurlijke karakter van onze sociale identiteiten opnieuw aan de orde stelt, een fundamentele kwestie voor het gehele onderzoeksveld. Inmiddels gaat het hier allang niet meer om de constructie van vrouwelijkheid alleen, maar om de manieren waarop de identiteitsbepalende factoren van ondermeer gender, ras, leeftijd, klasse en nationaliteit elkaar doorsnijden en wederzijds definiëren. Dit intersectionele perspectief kan nader uitgewerkt worden aan de hand van transnationale adoptie, waarin het complexe samenspel tussen genoemde sociale variabelen bepaalt welke mensen adopteerbaar gemaakt kunnen worden en welke niet. Het transnationale adoptiegezin kan zodoende nieuw licht werpen op het inzicht dat het persoonlijke politiek is, zoals het tweede golf feminisme reeds benadrukte. Dat wil 
zeggen, transnationale adoptie laat zien dat het persoonlijke inmiddels geopolitieke dimensies heeft aangenomen.

Ik onderzoek hoe adoptieouders en geadopteerden hun gezinsidentiteit vormen in het spanningsveld tussen afstamming en zelfcreatie. Hierbij besteed ik met name aandacht aan de wijze waarop ze de middelen van literatuur en kunst inzetten om hun gezinsidentiteit gestalte te geven. Fictie speelt namelijk een hoofdrol in het weven van verwantschap door adoptiegezinnen. Tijdens deze openbare les wil ik de nauwe samenhang tussen adoptie en fictie nader uiteen zetten.

Om onderscheid aan te brengen tussen pleegouders en adoptieouders onderwerpt de wet adoptie aan een biopolitieke norm. A doptie wordt begrepen als het aangaan van familiebetrekkingen tussen 1 of 2 volwassenen en 1 of meerdere minderjarigen als ware er sprake van afstamming. Adoptieouders kunnen dus allen virtuele wijze aan deze norm voldoen, in de sfeer van het doen alsof of de wereld van het als het ware. Dit nu is precies de modaliteit van fictie. Fictie vat ik hierbij op als het geheel van kunstgrepen die zintuigelijk waarneembare voorstellingen scheppen van mogelijke werelden. De scheidslijn tussen de wereld van het als het ware en de sociale werkelijkheid is vloeiend. De mogelijke werelden van fictie kunnen onderdeel worden van de sociale werkelijkheid wanneer voldoende mensen hun gedrag modelleren naar de voorbeelden van fictionele personages.Daarnaast is fictie in staat om verleden tijden aan de vergetelheid te ontrukken, of aspecten van de werkelijkheid te articuleren die te pijnlijk zijn om direct benoemd te worden in regulier taalgebruik. Fictie moet dus niet worden opgevat als het tegenovergestelde van feit, als 
onwaarheid of leugen, maar als een afgeleide van het Latijnse werkwoord fingere, wat zoveel betekent als vormen, construeren, maken.

Vele adoptieouders hebben zich middels fictie ingespannen om aan de biopolitieke norm te voldoen. Zij produceren talrijke memoires en autobiografieën, biopics, blogs, vlogs, youtube kanalen met hun eigen home movies, facebookpagina's, en websites voor virtuele gemeenschappen van adoptieouders. Deze autobiografische exercities zijn dikwijls direct geadresseerd aan hun geadopteerde kinderen, om hen van een familiegeschiedenis te voorzien.

Naast autobiografisch schrijven in de breedste zin des woords is kinderliteratuur een veelbeproefd middel om concrete gestalte te geven aan de virtuele familieband. De vroegste geschiedenis van geadopteerden is immers dikwijls in nevelen gehuld. Zodoende is het nooit eenvoudig om de vraag “waar kom ik vandaan?” te beantwoorden als ze wordt opgeworpen door een adoptiekind. Vandaar dat fictie wordt aangewend om concrete voorstellingen te maken van hoe het mogelijkerwijs geweest had kunnen zijn. Met name kinderboekenschrijvers hebben zich beijverd om oorsprongsverhalen te fingeren. Inmiddels is er een bloeiende nichemarkt ontstaan van kinderboeken over adoptie, geschreven door adoptieouders, om andere adoptieouders te ondersteunen bij de fabricage van oorsprongsverhalen voor hun kinderen.

Sinds de laatste eeuwwisseling valt tevens een ander geluid te beluisteren in het verwantschapsdiscours van adoptieouders, namelijk een bewuste, openlijke keuze voor 
gezinsidentiteit als constructie of zelf-creatie. Deze ouders verwerpen de biopolitieke norm nadrukkelijk, ten gunste van een monter multiculturalisme, dat de verschillen tussen mensen omarmt, en de vrije zelfstylering viert. Ook zij zijn aangewezen op fictie voor dit proces van zelf-creatie.

Verwantschap weven middels autobiografisch schrijven en kinderliteratuur streeft geen originaliteit of esthetische vernieuwing na. Integendeel, auteurs vallen juist graag terug op de bekende schablonen en iconen uit de Westerse literatuur en cultuur, hier en daar gelardeerd met een snufje exoticisme uit de cultuur van het zendende land. De vertelpraktijken van adoptieouders zijn dermate sterk voorgestructureerd, dat men hier van “productieve receptie” kan spreken. Deze term uit de literatuurwetenschappelijke bestudering van lezersgedrag verwijst naar het verschijnsel dat intensieve lezing van bestaande werken niet alleen uitmondt in secundaire literatuur zoals recensies en essays, maar ook aanleiding kan zijn tot een nieuw primair werk. Zo werkt het ook adoptieouders, die sprookjes en volksverhalen herschrijven, zoals Assepoester, klassiekers uit de sentimentele literaire traditie aanpassen aan eigen doeleinden zoals Oliver Twist, of beroemde Oriëntalistische fantasieën bewerken zoals de opera Madama Butterfly van Giacomo Puccini.

Niet alleen adoptieouders hanteren de middelen van kunst en literatuur om hun weg te bepalen door het spanningsveld tussen afstamming en zelf-creatie. Ook geadopteerden grijpen dikwijls naar de pen of naar welk ander beschikbaar medium dan ook, om verder te weven aan het verwantschapsweefsel. Hierbij hebben zij niet noodzakelijkerwijs hun adoptieouders op het oog. Doorgaans worden ze veel meer gebiologeerd door hun 
eerste ouders, hun eerste familie, hun geboorteland ergens aan de andere kant van de wereld. Ze getroosten zich dikwijls vergaande inspanningen om hun persoonlijke genealogie te traceren. Bepaald geen sinecure, omdat adoptie wordt verhuld door schaamte in de zendende landen, en door vergeten in de ontvangende landen. Geadopteerden bedienen zich daarom noodgedwongen van fictie in hun strijd tegen de gemankeerde culturele herinnering. Alleen fictie kan immers het afwezige aanwezig stellen, vergeten doorbreken, en stem geven aan diegenen die nog niet hebben kunnen spreken.

Laten we nu eens van naderbij bekijken hoe een en ander in zijn werk gaat. Wanneer we de culturele producti evan adoptieouders bestuderen, dan valt het op dat zij het arsenaal van de Westerse verteltraditie inzetten om te suggereren dat hun gezinnen zijn gevormd door voorbestemming en uitverkiezing. Toeval wordt omgebogen naar 'het-heeft-zo-moeten-zijn'. Verhalen van adoptieouders geven de idee gestalte dat dit specifieke kind aan deze specifieke ouders is toegewezen door een hogere macht. Voorbestemming en uitverkiezing maken de totstandkoming van het adoptiegezin minstens even onherroepelijk als gezinnen die zijn gebaseerd op afstamming.

Dit kan geïllustreerd worden aan de hand van een specifieke verwantschapsmetafoor die wijd verspreid is in eigentijdse kinderboeken over adoptie uit China, namelijk de metafoor van de zogenaamde rode draad. Hopelijk kan ik mij nu een stukje autoplagiaat permitteren, want wat ik hier ga zeggen is gebaseerd op een artikel dat ik heb geschreven met Macarena Garcia Gonzalez. Het beeld van de rode draad is ontleend aan een Chinees volksverhaal dat 
gaat over matchmaking in de context van gearrangeerde huwelijken. Dit verhaal wil dat toekomstige echtgenoten van geboorte af aan met elkaar verbonden zijn door een onzichtbare draad. Wanneer je trekt aan deze draad van het lot dan kom je elkaar naderbij tot het punt waarop het voorbestemde huwelijk kan worden gesloten. Dit beeld krijgt een geheel eigen vertaling en inkleuring in de kinderliteratuur over adoptie uit China, getuige bij voorbeeld het veelverkochte kinderboek The Red Thread: An Adoption Fairy Tale. Dit boek gaat over een kinderloos koninklijk echtpaar dat lijdt aan een snijdende pijn in het hart. Pas wanneer ze toverbrillen kopen van een marskramer ontdekken ze wat deze pijn veroorzaakt: er wordt aan hun hart getrokken door middel van een rode draad. Het koningspaar besluit om de draad te volgen om zo te ontdekken wie er aan hun touwtjes trekt. Het wordt een lange en barre tocht die hen leidt naar een Orientaals, armoedig oord en een klein meisje aldaar, dat de touwtjes in handen heeft en het vorstelijk paar actief naar zich toe trekt. De dorpelingen die het meisje omringen en geen van allen een duidelijke familieband met haar lijken te hebben, zijn er onmiddellijk van overtuigd dat dit kind voorbestemd is om overgedragen te worden aan dit echtpaar. Zo vinden de koning en de koningin hun prinsesje, een drastische statusverhoging voor dit meisje van onbestemde, maar in ieder geval nederige komaf.

\section{U zou zich af kunnen vragen waarom een onzichtbare} draad een kleur moet hebben. Dit komt volgens ons, omdat rood de kleur van het bloed is, zodat de rode draad als een equivalent van de navelstreng kan gelden: één van de vele pogingen van adoptieouders om aan de biopolitieke norm te voldoen door middel van fictie. 
De vertaalslag van een Chinees volksverhaal naar het eigentijdse kinderboek brengt een aantal verschuivingen en verdichtingen met zich mee. Het gearrangeerde huwelijk wordt hier vervangen door het gearrangeerde gezin. Overigens verdwijnen de connotaties van de verbintenis tussen man en vrouw hierbij niet volledig uit beeld, ze worden alleen verschoven naar paarvorming op grond van Romantische liefde. Romantische minnaars vertellen elkaar graag dat hun verbintenis een "match made in heaven" is, dat ze geboren of gemaakt zijn om elkaar te beminnen. Adoptieouders reppen van liefde op het eerste gezicht wanneer ze hun adoptiekind voor het eerst in hun armen sluiten. Je hart wordt gestolen. Het heeft zo moeten zijn. En liefde is altijd overvloeiende, zoals blijkt uit de illustraties in Karen Acres' kinderboek Little Miss Ladybug \& Her Magical Red Thread, dat een variant biedt op het motief van de rode draad. Hier wordt de draad van het lot geweven door een lieveheersbeestje, symbolische brenger van geluk. Overigens ziet u ook hier weer een poging om het adoptieproces een natuurlijk, organisch karakter te geven. Adoptiekindjes groeien in bloemknoppen, net zoals Duimelijntje in het gelijknamige sprookje van Hans Christian Andersen, en het weven van verwantschap is even natuurlijk als het weven van een web.

Naast deze pogingen om adoptie een natuurlijk karakter te geven, worden er ook kinderboeken gepubliceerd die de oorsprongskwestie en de daarmee samenhangende associatie van natuurlijkheid nadrukkelijk terzijde schuiven. Het kinderboek We Belong Together: A Book About Adoption and Families van Todd Parr bij voorbeeld, stelt dat adoptiekinderen en adoptieouders bij elkaar horen simpelweg omdat adoptieouders de behoeftes van 
adoptiekinderen weten te vervullen. Moraal van dit verhaal: "There are lots of different ways to make a family. It just takes love. Share your home, and share your heart. Love, Todd”. Een ander boek van zijn hand, It's Okay to be Different, laat een grote hoeveelheid verschillende manieren om 'anders'te zijn de revue passeren, waaronder twee vaders of twee moeders hebben of geadopteerd zijn. Moraal van dit verhaal: "It's okay to be different. You are special and important just because of being who you are. Love, Todd”. Hier zien we hoe het adoptiegezin een symbool wordt van maatschappelijke verdraagzaamheid.

De gemeenplaatsen van voorbestemming en uitverkiezing tillen het weven van verwantschap met kinderen uit andere werelddelen naar een hoger metafysisch plan. Hierbij geraken de specifieke historische en politieke factoren die kinderen adopteerbaar hebben gemaakt buiten beeld. "Er was eens", de tijd van het sprookje, voert altijd weg van de tijd van de geschiedenis. Dit collectieve vergeten is niet alleen aan de orde in kinderliteratuur. In het algemeen is er in de ontvangende landen bijzonder weinig kennis overgebleven van de factoren die de uittocht van kinderen uit de zendende landen hebben ontketend. Gemankeerde herinnering in de ontvangende landen wordt versterkt door schaamte en taboes omtrent adoptie in de zendende landen. En de grote talige en culturele barrières tussen zendende en ontvangende landen maken de zaak er ook niet gemakkelijker op.

Behalve een enkele onderzoeker hier of daar die zich de moeite getroost om de taal van een zendend land te leren en onderzoek te doen ter plekke, zijn het momenteel vooral de geadopteerden uit Korea die zich inspannen om de gemankeerde culturele herinnering te herstellen aan de 
factoren die tot de mondiale verplaatsing hebben geleid van ongeveer 200.000 Koreaanse kinderen. Ook geadopteerden proberen het contingente karakter van hun familie- identiteit om te buigen tot essentie, door op zoek te gaan naar hun oorsprong. Zij leiden volgens eigen zeggen gespleten levens, waarin ze zich achtervolgd weten door spoken uit hun vroege verleden. Het meisje dat opgroeide als, bij voorbeeld, Jane Brauer in de rurale gemeenschap van Harlow, Minnesota, was ooit geboren als Kyong-Ah in Korea, als derde dochter van haar Koreaanse eerste moeder. Kyong-Ah bestaat in zekere zin niet meer. Haar levenslijn is vroegtijdig afgebroken, maar nooit volledig uitgewist. Ze is nooit echt gestorven en begraven. Vandaar dat ze nog steeds rondspookt in het leven van Jane Brauer. Soms worden geadopteerden zelfs achtervolgd door meerdere schimmen uit het verleden, wanneer er met hun persoonsgegevens is geknoeid, bij voorbeeld, om het ene Koreaanse kind te kunnen vervangen door het andere. Adoptieouders merken het verschil toch niet. Deann Borshay Liem maakt gewag van een dergelijke kinderruil in haar autobiografische film In the Matter of Cha Jung Hee.

Geadopteerden verlangen naar hereniging en verzoening met het kind dat ze ooit zijn geweest. Inmiddels is er een ware cultuurindustrie ontstaan omtrent de zogenaamde root trips van geadopteerden, compleet met commerciële tour operators en betaalde speurneuzen die geadopteerden aan hun eerste ouders proberen te koppelen. Sommige geadopteerden besluiten zelfs permanent te remigreren naar hun geboorteland, in de hoop daar eindelijk te mogen ervaren dat ze ergens bij horen. Deze hoop blijkt doorgaans tevergeefs, wat overigens nog niet impliceert dat root trips en remigratie zinloos zouden zijn. Met de terugkeer van 
geadopteerden naar Korea ontstaat een kleine, maar

beeldbepalende groep activisten die zowel het Engels als het Koreaans beheersen en ter plekke onderzoek kunnen doen naar de factoren die hun exodus hebben veroorzaakt. Het autobiografische schrijven van geadopteerden wordt zodoende gekenmerkt door twee tegenstrijdige, maar onderling samenhangende tendensen, namelijk het verlangen om hun identiteit op essentialistische wijze te herijken op hun oorsprong en het streven om de contingente politieke en sociale omstandigheden die leidden tot adoptie uit de taboesfeer te halen.

In de autobiografie The Language of Blood beschrijft Jane Jeong Trenka haar pogingen om haar verscheurdheid tussen Jane Brauer en Kyong-Ah op te heffen tijdens diverse root trips naar Korea. Deze reizen gaan gepaard aan sterk fysiek getinte dagdromen over terugkeer naar de moederschoot, of over de terugname van haar eerste moeder en alles wat bij haar hoort in Trenka's eigen schoot. In het vervolg op The Language of Blood, Fugitive Visions, is Trenka minder optimistisch over haar mogelijkheden tot wedergeboorte als Koreaanse. Inmiddels permanent gevestigd in Korea, blijkt de taal van het bloed niet bij machte om haar innerlijke verdeeldheid te helen. Alles wat haar nu rest zijn glimpsen van de factoren die haar tot een verdeeld subject hebben gemaakt. Die verdeeldheid echter treft niet alleen Trenka als individu:

In this country that pulses with the collective memory of an unfinished war, an artificial boundary etched through the middle of her body and the collective imprint of a desperation that will not go away, I am still at war with myself. How does one live in the condition of being separated from oneself? 
Zoals deze passage illustreert, zijn Trenka’s persoonlijke lotgevallen inmiddels volledig verknoopt geraakt met de geschiedenis van Korea. In stukjes en beetjes komt het eruit: haar gewelddadige eerste vader die haar eerste moeder verdacht van ontucht met Amerikaanse soldaten.. Zijn wantrouwen valt niet geheel uit de lucht. Amerikaanse soldaten bezetten in de jaren vijftig dezelfde legerbases die tot 1945 door de Japanners werden bezet, toen Korea nog een kolonie van Japan was. Toen Japan mobiliseerde voor de oorlogen met andere landen rondom de Stille Oceaan tussen 1931 en 1945, werden de militaire bases voorzien van zogenaamde "comfort stations," de plekken waar de ook ons welbekende troostmeisjes onder dwang Japanse soldaten moesten gerieven. Deze troostmeisjes werden gerecruteerd uit geheel Zuid-Oost Azië, inclusief voormalig Nederlands-Indië, maar ze bestonden voor ongeveer 70 procent uit Koreaanse vrouwen. Deze vrouwen konden na afloop van de oorlog niet meer terug naar hun familie, omdat ze bezoedeld waren in hun ogen. Velen waren daarom gedwongen om hun bestaan als sekswerker voort te zetten, deze keer in dienst van de Amerikaanse soldaten die de Japanners inmiddels waren opgevolgd. Het Amerikaanse leger erfde zo de hele infrastructuur van de troostmeisjes van de Japanners. Ook de Koreaanse vrouwen die zonder betaling seks hadden met Amerikaanse soldaten, werden met de nek aangekeken. Hetzelfde geldt voor de kinderen die uit deze allianties voortkwamen, getuige het levensbedreigende fysieke geweld dat hun eerste vader pleegde tegen Kyong-Ah en haar oudere zuster Mi-Ja, later Jane en Carol. Dit bracht hun eerste moeder er destijds toe om de zusjes beschikbaar te stellen voor adoptie. In een film die in belangrijke mate geinspireerd is door Trenka's Fugitive Visions, getiteld The 
Woman, the Orphan and the Tiger, wordt de

lotsverbondenheid van drie generaties Koreaanse vrouwen nadrukkelijk in beeld gebracht, te weten de troostmeisjes voor Japanse militairen, de Koreaanse sekswerkers rondom de Amerikaanse legerbases, en de kinderen die uit deze betrekkingen voortkwamen. Deze vrouwen zijn tezamen verstrikt geraakt in één moeilijk te ontwarren kluwen van seksisme en racisme:

"Comfort child," het woord blijft als een graat in je keel steken. Deze pregnante uitdrukking roept in al haar beknoptheid bijzonder moeilijke vragen op. Ze suggereert onomwonden dat transnationale adoptie een voortzetting is van de koloniale en imperialistische regimes die opeenvolgende generaties van Koreaanse vrouwen onderwierpen aan sociale groepen met grotere politieke, militaire en economische macht. Voorstanders van transnationale adoptie daarentegen zien adoptie juist als een middel om de uitwassen van kolonialisme en imperialisme te verzachten, door verworpen kinderen om te toveren in uitverkorenen. In hun ogen is het transraciale adoptie gezin een symbool van een inclusieve mondiale samenleving. Hier botsen twee tegenovergestelde perspectieven frontaal op elkaar. Ze worden beiden even luid verdedigd in de heftige maatschappelijke controversen waaraan transnationale adoptie vandaag de dag gepaard gaat. Kan adoptieve gezinsvorming die voortvloeit uit seksisme en racisme in een belangrijk zendend land, veranderen in een antiracistische en anti-seksistische praktijk in de ontvangende landen? Is er een perspectief denkbaar van waaruit zowel de zendende als de ontvangende landen gelijkelijk in het weven van verwantschap betrokken kunnen worden? Dit zijn geen gemakkelijke vragen, en zeker ook niet voor 
mij, als directeur van het Centrum voor Gender en

Diversiteit dat, zoals onze website vermeldt, wetenschappelijk onderzoek verricht in dienst van een inclusieve samenleving. Ook ik zou het menselijk vermogen tot bonding voorbij de grote sociale verschillen willen onderschrijven. Ook ik ben ervan doordrongen dat de familiebanden die ontstaan door dagelijkse omgang en zorg minstens even belangrijk, eigenlijk veel belangrijker zijn dan genetische verwantschap. Dit zijn stuk voor stuk waarden die ook worden omarmd door de voorstanders van transnationale adoptie. Maar tegen welke prijs?

Gegeven de complexiteit van de opgeworpen vragen stel ik voor dat we ook hier te rade gaan bij fictie. Ter afronding van deze openbare les wil ik u daarom uitnodigen de eerste minuten te bekijken van de film Adopting Belinda.

In deze korte film passeren alle cliché's de revue van adoptiediscours in de ontvangende landen. Het gaat om een typisch middenklasse echtpaar, woonachtig in suburbia. Ze wringen zich in allerlei kronkels en bochten om het natuurlijke karakter van adoptie te beklemtonen. Ze dragen Deense namen, Anderson, en ze wilden per se een Deens kindje adopteren omdat ze zelf Deense roots hebben. Dankzij hun gemeenschappelijke achtergrond heeft Belinda hoegenaamd geen aanpassingsproblemen gehad, zo vermeldt de adoptievader tevreden. Kijkers ervaren hun ietwat zelfgenoegzame beweringen al snel als ongerijmd. Bij Deense roots stellen we ons geen mensen voor met een Aziatisch uiterlijk. De ironie wil echter dat hun uitspraken uiterst plausibel zijn, wanneer men ze beschouwt in de context van transnationale adoptie. Het is heel goed mogelijk dat dit echtpaar Anderson heet, Denemarken adopteerde namelijk het hoogste aantal Koreaanse kinderen 
per capita. In dat geval heeft dit echtpaar inderdaad Deense roots en zeggen ze geen woord te veel wanneer ze aangeven dat ze een kindje willen met vergelijkbare achtergrond. De dubbele ironie wil dat u hier kijkt naar filmmaker en performance kunstenares Jane Jin Kaisen, geadopteerd uit Korea en opgegroeid in Denemarken, maker van de film The Woman, the Orphan and the Tiger waar u zojuist een scène uit zag. Zij wordt geflankeerd door Tobias Hübinette, adoptie-onderzoeker en activist, eveneens van Koreaanse origine en opgegroeid in Zweden. Het is dus letterlijk waar dat dit duo Scandinavische roots heeft.

De 'mockumentary' Adopting Belinda maakt door middel van de klassieke fictionele kunstgrepen van omkering en ironie duidelijk dat nationaliteit veel meer inhoudt dan het staatsburgerschap van een bepaalde natie alleen. Nationaliteit heeft ook stilzwijgende raciale implicaties. Adopting Belinda werpt de vraag op in hoeverre ontvangende landen het hybride subject dat uit transnationale adoptie voortkomt daadwerkelijk erkennen. Als we bij de uitdrukking "Danish roots” ogenblikkelijk denken aan witte mensen en niet in staat zijn om de hoofdrolspelers in de film daarmee te associëren, in hoeverre kunnen geadopteerden dan ooit volwaardige staatsburgers worden in de ontvangende landen? Adopting Belinda onthult tevens hoe vanzelfsprekend wij het vinden dat adoptie éénrichtingsverkeer is. Adoptie gaat van gekleurd naar wit, van Oost naar West, van Zuid naar Noord, niet andersom. Het nobele streven van dit echtpaar om in hun eigen woorden, niet slechts Belinda, maar heel Denemarken vooruit te helpen, werpt de vraag op in hoeverre Westerse landen zich vooruit geholpen zouden voelen door de verwijdering van hun kinderen. 
Een begin van een antwoord op de zojuist opgeworpen vragen is volgens het gedachtenexperiment, dat we adoptie van alle windstreken naar alle windstreken moeten kunnen willen, om transnationale adoptie te kunnen willen. Het transnationale en transraciale adoptiegezin kan wat mij betreft heel goed gehandhaafd blijven als symbool van een inclusieve mondiale samenleving, als icoon van the family of men, gesteld dat we adoptie symmetrisch zouden kunnen en willen organiseren. Maar als Belinda niet adopteerbaar gemaakt kan worden, wie dan eigenlijk wel?

Dames en heren, ik hoop u ervan overtuigd te hebben dat de vertelpraktijken van adoptiegezinnen een relevant onderzoeksobject bieden aan genderstudies.

Verhaalschablonen, metaforen en iconen zijn gestolde waarden die impliciet duiden wat het betekent om familie te zijn. De cultuurwetenschap is bij machte om deze impliciete waarden te expliciteren en daarmee toegankelijk te maken voor reflectie en debat. Zij volgt daarbij soms het reflexieve potentieel van fictie zelf, dat stilzwijgende aannames op speelse wijze ter discussie kan stellen, getuige Adopting Belinda. Zowel fictie als haar wetenschappelijke bestudering dragen er wezenlijk toe bij dat het collectieve vergeten omtrent de politieke en maatschappelijke factoren die kinderen adopteerbaar maken wordt doorbroken. Dit is bepaald geen overbodige luxe, gegeven het zojuist genoemde controversiële karakter van transnationale adoptie.

Cultuurwetenschappelijk onderzoek vanuit intersectioneel perspectief is niet alleen waardevol voor de adoptiepraktijk, hetzelfde geldt andersom: de cultuurwetenschap wordt verrijkt door adoptiestudies. In 
concreto kunnen culturele adoptiestudies een nieuwe impuls geven aan het receptie-onderzoek, door niet alleen te bestuderen hoe lezers of toeschouwers waarde en betekenis toekennen aan klassiekers, maar ook hoe zij klassiekers inzetten om sociale praktijken vorm te geven, in dit geval, het weven van verwantschap. Ik hoop mij de komende jaren dan ook in te zetten voor internationaal vergelijkend onderzoek naar adoptieve vertelpraktijken in met name de Europese ontvangende landen, die tot dusverre veel minder bestudeerd zijn dan de

Amerikaanse adoptiecultuur. Meer in het algemeen, zal ik de Opzij-stoel in dienst stellen van wat Nira YuvalDavis "the politics of belonging” noemde, dat wil zeggen, het maatschappelijk vraagstuk wie waar het recht geniet om erbij te mogen horen en thuis te zijn in onze globaliserende wereld. Hierbij zal ik met name aandacht geven aan de wereldwijde verplaatsingen van kinderen.

En dan is nu het moment voor een dankwoord aangebroken. Ik dank in de eerste plaats de Faculteit der Cultuur- en Maatschappijwetenschappen, in concreto Rein de Wilde en André Koehorst, die mij in staat stellen om het zojuist beschreven onderzoek te verrichten als directeur van het Centrum voor Gender en Diversiteit, en ik dank de Stichting Opzij voor mijn aanstelling als bijzonder hoogleraar Culturele herinnering, gender en diversiteit. Ik vind het een eer dat ik na Maaike Meijer, Liesbet van Zoonen, Marli Huijer en Ineke Boerefijn de vijfde bezetter van deze leerstoel mag zijn.

Van mijn jarenlange collegiale en vriendschappelijke verbintenis met Maaike Meijer heb ik geleerd: gender en diversiteit, dat is vlijt, strijd en jolijt. Mineke Bosch speelde een leidende rol in de oprichting van het Centrum voor Gender en Diversiteit, en daarom schenkt het me veel 
genoegen dat ik hier vandaag in haar toga mag staan. Trots ben ik ook op de grote wetenschappelijke kwaliteiten van mijn naaste collega's in het Centrum voor Gender en Diversiteit: Agnes Andeweg, Ulrike Brunottte, Louis van den Hengel, Aagje Swinnen. Ik durf te zeggen dat wij een eigen geluid laten horen in de bestudering van de maatschappelijke functionaliteit van literatuur en kunst, in samenwerking met de capaciteitsgroep Letteren en Kunst en de onderzoeksgroep Arts, Media and Culture, geleid door Renée van de Vall. Hierbij spelen onze assistenten-inopleiding Christophe van Eecke, Elena Fronk, Codruta Pohrib en Constance Sommerey ook een vitale rol. Ik verheug me in de samenwerking met Valentina Mazzucato en Julia Vich in het onderzoek naar transnational families binnen de context van het Maastricht Centre for Citizenship, Migration and Development (MACIMIDE). Binnen de nationale context ben ik dankbaar voor samenwerking met de Nederlandse Onderzoeksschool Genderstudies in het algemeen, en met Rosemarie Buikema in het bijzonder. My work has profited significantly from international collaboration within the Alliance for the Study of Adoption and Culture, especially with Claudia Nelson, and the International Research Society for Children's literature, especially with Mavis Reimer. I am also very happy that the international collaborative research project PIACIM, Platform for a Cultural History of Children's Media, will be continued into the future, thanks to a renewed grant of the Dutch Science Foundation. Meer in het bijzonder wil ik in dit verband Helma van Lierop en Vanessa Joosen bedanken voor hun trouwe collegiale samenwerking bij de wetenschappelijke bestudering van de kinder- en jeugdliteratuur. Deze invalshoek leidde tot het eveneens door NWO gefinancierde MaastrichtsTilburgse onderzoeksproject Emergent Cultural Literacy, 
waarin ik mag samenwerken met ondermeer Herman Beck, Annette de Bruijn, Karen Ghonem, Maaike Meijer en Inge Verouden. En tenslotte mag Racheel Wennek, onze office manager, niet onvermeld blijven, die al deze activiteiten organisatorisch ondersteunt, als opvolger van de even zo verdienstelijke Wilma Lieben.

Een persoonlijk woord van dank gaat uit naar Norbert Bonenkamp, met wie ik onze drie kinderen heb verzorgd en opgevoed, en naar Maurits, Tim, en Esther. Jullie van zo dichtbij te zien opgroeien is het grootste voorrecht dat ik tot dusverre in mijn leven heb genoten. Mijn zeven broers en zussen, inmiddels helaas zes, en mijn zes schoonzussen en zwagers, inmiddels helaas vijf, hebben mij geleerd dat bloedverwanten evenzogoed hun verwantschap weven. Kinderen, familie, vrienden en vriendinnen, collega's: hartelijk dank!

Ik heb gezegd. 
